\title{
Características de carcaça, componentes não-carcaça e composição tecidual e química da 12a costela de cordeiros Santa Inês terminados em pasto com três gramíneas no período seco
}

\author{
Luizângele Figueiredo de Oliveira Menezes ${ }^{1}$, Helder Louvandini², Geraldo Bueno Martha \\ Júnior $^{3}$, Concepta McManus ${ }^{2}$, José Américo Soares Garcia ${ }^{2}$, Luci Sayori Murata ${ }^{2}$
}

\footnotetext{
${ }^{1}$ Mestrando - Faculdade de Agronomia e Medicina Veterinária, Universidade de Brasília, CEP: 70910-900, Brasília, DF.

2 Faculdade de Agronomia e Medicina Veterinária, Universidade de Brasília, CEP: 70910-900, Brasília, DF.

${ }^{3}$ Embrapa Cerrados, BR 020 Km 18, CEP: 73310-970,Caixa Postal 08223, Planaltina, DF.
}

RESUMO - Foram avaliadas as características de carcaça, os componentes não-carcaça e o rendimento da $12^{2}$ a costela de cordeiros Santa Inês terminados em pastejo rotacionado com três forrageiras tropicais (A. gayanus Kunth, cv. Planaltina, P. maximum Jacq., cv. Aruana e P. maximum Jacq., cv. Tanzânia), no período seco do ano. Utilizou-se delineamento inteiramente casualizado, com 11 ovinos (3 meses de idade e 18,8 \pm 2,88 kg PV) em cada tratamento. Os animais receberam suplementação com concentrado em níveis crescentes, conforme o avançar do período seco, além de sal mineral à vontade. Ao final de 82 dias de experimento, os animais foram abatidos; no dia anterior ao abate, a área de olho-de-lombo (AOL) foi mensurada com ultrasom (AOLUS). Avaliaram-se o peso ao abate (PA), o peso de carcaça quente (PCQ), o rendimento de carcaça quente (RCQ), o comprimento da carcaça (CC), o escore de gordura subcutânea (EGS), o peso da meia-carcaça quente (PMCQ), os cortes da meiacarcaça (costela/fralda, costeleta, lombo, paleta, pernil, e pescoço) e os pesos da pele (PELE), das vísceras torácicas (VT) e abdominais (VA) e dos testículos (TE). A 12aㅡ costela foi avaliada quanto ao peso total (PT), AOL, aos pesos e às porcentagens de músculo (MUSC), osso (OSSO) e gordura (GORD) e os constituintes químicos. As características PA, PCQ, RCQ, PELE e GORD não diferiram entre os animais terminados em pastos de capim-aruana e capim-tanzânia, mas foram superiores nos animais terminados em pasto de capim-andropogon. Os rendimentos de pescoço, costela/fralda e costeleta dos animais terminados em capim-tanzânia foram superiores aos obtidos nos animais terminados em capim-andropogon e aruana, que não diferiram entre si. As demais características de carcaça, dos componentes não-carcaça e da 12a costela não diferiram entre os tratamentos. Os ovinos mantidos em pastagem de capim-aruana e capim-tanzânia apresentaram melhores características de carcaça e desempenho mais satisfatório em comparação aos terminados em pasto de capim-andropogon.

Palavras-chave: Andropogon, Aruana, nutrição, Tanzânia, ultra-sonografia

\section{Carcass traits, non-carcass components and tissues and chemical composition the $12^{\text {th }}$ rib of Santa Inês sheep finished on three different grasses during the dry season}

ABSTRACT - Carcass traits, non-carcass components and $12^{\text {th }}$ rib yield of Santa Inês sheep finished in rotational grazing with three different tropical grasses (A. gayanus Kunth. cv. Planaltina, P. maximum Jacq. cv. Aruana and P. maximum Jacq. cv. Tanzania) were evaluated in the dry season of the year. A completely randomized design with 11 sheep (3 months old and $18.8 \pm 2.88 \mathrm{~kg} \mathrm{LW}$ ) in each treatment was used. Animals were supplemented with increasing levels of concentrate, as advancing of the dry season, besides ad libitum mineral salt. At the end of 82 days of experiment, the animals were slaughtered, in the previous day of the slaughter; loin eye area (LYA) was measured using ultra-sound (EMUS). Carcasses were evaluated for slaughter weight (SW), hot carcass weight (HCW), hot carcass dressing (HCD), carcass length (CL), subcutaneous fat score (SFATS), hot half carcass weight (HHCW), half carcass cuts (Rib/Belly, Rack, Back, Shoulder, Leg and Neck), skin weight (SKIN), thoracic (TV) and abdominal (AV) viscera and testicular (TE). The $12^{\text {th }}$ rib was evaluated for total weight (TW), LYA, amount and percentage of muscle (MUSC), bone (BONE) and fat (FAT) as well as chemical composition. The characteristics SW, HCD, HHCW, SKIN and FAT did not differ between animals finished on Aruana and Tanzania grass, however were superior to those on andropogon grass. The yields on Neck, Rib/Belly and Rack in animals finished in tanzânia grass was superior to those on andropogon grass and aruana grass, which did not differ between itself. The other carcass traits, non-carcass components and $12^{\text {th }}$ rib analyses did not differ between treatments. Sheep kept on aruana grass and tanzania grass howed better carcass traits with more satisfactory production levels when compared to the animals finished on andropogon grass.

Key Words: Andropogon, Aruana, nutrition, Tanzania, ultrasonography 


\section{Introdução}

A produção de carne é uma atividade em ascensão na ovinocultura brasileira (Siqueira et al., 2001), embora o mercado consumidor seja exigente quanto à sua qualidade. Entretanto, a oferta da carne ovina ainda é bastante irregular, em virtude da baixa tecnologia empregada nos sistemas de produção (SEBRAE, 2005).

A conformação da carcaça éimportante na comercialização, uma vez que as características desejáveis e de maior valor comercial implicam morfologia compacta, curta e larga, com pernas globosas e planos musculares desenvolvidos, com predominância de perfis convexos em todas as regiões corporais (Macedo et al., 2000), que possibilitam maiores porcentagens de cortes nobres (pernil e palheta), maior proporção de músculo e menores proporções de gordura e osso (Furusho-Garcia et al., 2003; Tonetto et al., 2004; Azeredo et al., 2006).

Resultados de pesquisas têm comprovado que a análise dos componentes da $12^{2}$ costela e da área de olho-de-lombo são bons indicadores da composição corporal e possibilitam a comparação entre diferentes grupos genéticos e manejos adotados (Louvandini et al., 2006). Outra forma de se realizar essas observações é o uso da ultra-sonografia, que possibilita boa estimativa da massa muscular e auxilia na determinação da melhor época de abate do animal ainda vivo (McLaren et al., 1991; Hougthon \& Turlingthon, 1992; Berg et al., 1997).

Segundo Furusho-Garcia et al. (2003), a comercialização de cordeiros se baseia apenas na observação do peso dos animais, mas, para melhor interação entre os interesses de produtores e consumidores, é necessário o conhecimento da composição percentual dos cortes e de outras partes que compõe o peso dos animais e caracterizam a qualidade do produto.

Nesse sentido, os componentes não-carcaça, também chamados "quinto quarto", podem ser utilizados como fator de interesse comercial, pois possibilitam maior valorização do animal abatido e maior motivação aos cuidados sanitários do rebanho e consiste em alternativa alimentar para as populações de baixa renda (Jardim et al., 2002; Mendonça et al., 2003; Frescura et al., 2005).

Um dos grandes desafios do setor é garantir quantidade suficiente de animais para abate em condições uniformes de carcaça. A fase de recria-terminação na Região CentroOeste geralmente ocorre em pastejo, mesmo durante o período seco, quando a baixa qualidade e disponibilidade de forragem agravam ainda mais a situação. Assim, o desafio no uso de gramíneas forrageiras melhoradas na criação de ovinos visa minimizar o problema da sazonalidade. Neste trabalho, objetivou-se avaliar as características de carcaça, da $12^{\text {a }}$ costela e dos componentes não-carcaça de cordeiros Santa Inês terminados em pastejo com os capins Andropogon, Aruana e Tanzânia durante o período seco do ano.

\section{Material e Métodos}

A pesquisa foi conduzida na Fazenda Água Limpa, da Universidade de Brasília (UnB), no período de junho a agosto de 2005, época caracterizada como seca. O delineamento experimental foi o inteiramente casualizado com três tratamentos, caracterizados pelas forrageiras Andropogon gayanus Kunth. cv. Planaltina, Panicum maximum Jacq. cv. Aruana e cv. Tanzânia. Foram utilizadas áreas de 1 hectare de cada gramínea, divididas em quatro subparcelas de 0,25 hectares. As pastagens com as gramíneas do gênero Panicum foram estabelecidas no período de dezembro de 2004 a fevereiro de 2005, com adubação N:P:K de 45:90:50 kg/ha e mais $15 \mathrm{~kg}$ de N/ha de cobertura, em substituição a áreas de pastagens degradadas de Andropogon. Uma área foi mantida com o capim-andropogon, em bom estado de conservação, e adubada com 60:90:50 kg/ha de NPK, com a finalidade de representar o tipo de pastagem utilizada pelos ovinocultores regionais. O pastejo rotacionado foi utilizado com período de ocupação de 14 dias e 42 dias de descanso, com taxa de lotação fixa de 22 animais/ha. Em cada tratamento, acompanhou-se o desenvolvimento de 11 cordeiros da raça Santa Inês, com idade média inicial de 90 dias e peso inicial de $18,8 \pm 2,88 \mathrm{~kg}$, por um período experimental de 82 dias.

Os animais receberam ao final do dia suplemento alimentar composto da seguinte mistura concentrada: $50 \%$ de milho moído, 30\% de farelo de soja e $20 \%$ de farelo de trigo. A quantidade ofertada foi crescente ao longo dos seis períodos de 14 dias - nos primeiros três períodos, 300 g/ animal/dia; no quarto e no quinto período, $400 \mathrm{~g} / \mathrm{animal} / \mathrm{dia}$; e no último período, $500 \mathrm{~g} / \mathrm{animal} / \mathrm{dia}$ - no intuito de corrigir as deficiências nutricionais das forrageiras com o avançar do período seco, descritas pelo Agricultural and Food Research Council (AFRC, 1993). O fornecimento de sal mineral (Nutron ${ }^{\circledR}$ ) foi à vontade. As análises bromatológicas dos alimentos foram realizadas conforme descrito por Silva \& Queiroz (2002) (Tabela 1).

A medição da área de olho-de-lombo por ultrasonografia (AOLUS) foi realizada um dia antes do abate com aparelho de ultra-som ALOKA ${ }^{\circledR}$, modelo SSD-500, equipado com transdutor de $5 \mathrm{MHz}$, após a tricotomia na área de medição, na região lombar da $12 \underline{\text { a }}$ costela, no espaço inter- 
Tabela 1 - Composição bromatológica do concentrado e dos capins andropogon, aruana e tanzânia

\begin{tabular}{|c|c|c|c|c|c|}
\hline \multirow[t]{2}{*}{ Variável } & \multirow[t]{2}{*}{ Concentrado } & \multicolumn{3}{|c|}{ Gramínea } & \multirow[t]{2}{*}{ EP } \\
\hline & & Andropogon & Aruana & Tanzânia & \\
\hline Matéria seca (\%) & $88,3 \pm 1,25$ & $47,1 \pm 6,37$ & $43,4 \pm 13,05$ & $40,8 \pm 13,56$ & 3,06 \\
\hline Proteína bruta & $21,7 \pm 0,60$ & $4,1 b \pm 1,38$ & $5,1 \mathrm{a} \pm 1,30$ & $4,2 b \pm 1,35$ & 0,35 \\
\hline Fibra em detergente neutro & $15,8 \pm 0,50$ & $74,3 \pm 11,16$ & $72,2 \pm 10,97$ & $72,7 \pm 10,80$ & 2,86 \\
\hline Fibra em detergente ácido & $7,3 \pm 0,17$ & $45,5 a \pm 10,56$ & $42,5 b \pm 10,72$ & $42,2 b \pm 10,82$ & 2,80 \\
\hline Extrato etéreo & $3,1 \pm 0,30$ & $1,5 b \pm 1,10$ & $2,1 \mathrm{a} \pm 1,14$ & $1,9 \mathrm{ab} \pm 1,19$ & 2,93 \\
\hline Matéria mineral & $3,2 \pm 0,30$ & $4,7 b \pm 1,40$ & $6,8 a \pm 1,87$ & $6,9 a \pm 1,50$ & 0,35 \\
\hline
\end{tabular}

Médias seguidas por letras diferentes, entre as gramíneas na mesma linha, apresentaram diferenças significativas $(P<0,05)$. $\mathrm{EP}=$ erro-padrão.

costal. Ao final dos 82 dias de período experimental, após jejum de sólidos (24 horas), os animais foram pesados para determinação do peso vivo ao abate (PA) e depois foram abatidos por insensibilização por eletrochoque, seguida de sangria e esfola. Realizou-se avaliação das características da carcaça, segundo metodologia adaptada de Osório et al. (1998). Foram determinados: o comprimento da carcaça (CC), medido da base da cauda à base do pescoço; o peso da carcaça quente (PCQ); o peso da meia-carcaça quente (PMCQ); e o escore de gordura de cobertura (EGC), que variou de 1 (muito magro) a 5 (muito gordo), em escala de 0,25 ponto. A meia-carcaça esquerda quente foi dividida nos cortes costela/fralda, costeleta, lombo, paleta, pernil e pescoço. Em seguida, mediram-se o peso e o rendimento de carcaça, obtido dividindo-se o PCQ pelo PA. Também foram mensurados os pesos da pele (PELE), das vísceras torácicas pulmões e coração (VT), das vísceras abdominais fígado e rins (VA) e dos testículos (TE).

As frações correspondentes à região da $11^{\underline{a}}$ a $13^{\underline{a}}$ costelas foram retiradas da meia-carcaça direita e congeladas a $-20^{\circ} \mathrm{C}$. Posteriormente, procedeu-se à separação da 12 a costela com uso de serra elétrica, com corte posterior a $11^{\mathrm{a}}$ costela e anterior a $13^{\underline{a}}$ costela, para determinação da área de olho-de-lombo na carcaça (AOL) pelo método do papel quadriculado $\left(1 \mathrm{~cm}^{2}\right)$. Em seguida, a $12^{\mathrm{a}}$ costela foi pesada (PT) e procedeu-se à separação e pesagem dos constituintes: músculo (MUSC), osso (OSSO) e gordura (GORD), segundo metodologia adaptada de Hankins \& Howe (1946). Todos os constituintes foram re-agrupados e levados à estufa $\left(65^{\circ} \mathrm{C}\right)$ durante 72 horas para análise dos teores de matéria seca (MS). Os componentes foram finamente moídos para as análises dos teores de proteína bruta (PB), matéria mineral (MM) e extrato etéreo (EE), segundo recomendações da Association of Official Agricultural Chemists (AOAC,1995).

As variáveis estudadas foram analisadas utilizando-se o modelo estatístico:

$$
\mathrm{Y}_{\mathrm{ij}}=\mu+\mathrm{P}_{\mathrm{i}}+\mathrm{E}_{\mathrm{ij}} \text {, }
$$

em que: $\mathrm{Y}_{\mathrm{ij}}=$ variável dependente observada nos tratamentos; $\mu=$ média observada em $\mathrm{Y}_{\mathrm{ij}} ; \mathrm{P}_{\mathrm{i}}=$ efeito do tratamento $\left(\mathrm{i}_{1}=\right.$ Andropogon; $\mathrm{i}_{2}=$ Aruana e $\mathrm{i}_{3}=$ Tanzânia); $\mathrm{E}_{\mathrm{ij}}=$ erro experimental associado a $\mathrm{Y}_{\mathrm{ij}}$.

O pacote estatístico Statistical Analysis System (SAS, 1999) foi utilizado, com procedimento GLM, para a análise dos dados. A diferenciação dos resultados dos tratamentos foi obtida com a aplicação dos procedimentos LSMEANS e PDIFF, pela diferenciação equivalente ao teste t, em que PA foi a co-variável para as características relacionadas à carcaça. O procedimento CORR foi utilizado para determinar a correlação entre as variáveis analisadas, adotando-se o nível de 5\% de significância.

\section{Resultados e Discussão}

As médias de peso ao abate (PA), peso da carcaça quente (PCQ) e rendimento da carcaça quente (RCQ) obtidos com os capins aruana e tanzânia não diferiram entre si $(\mathrm{P}>0,05)$, mas foram superiores às encontradas com $\mathrm{o}$ capim-andropogon $(\mathrm{P}<0,05)$ (Tabela 2$)$. Esses resultados estão relacionados à melhor disponibilidade de nutrientes nestas forrageiras (Aruana e Tanzânia) durante o período experimental (Tabela 1 ) e às maiores médias percentuais de lâminas foliares na composição de suas massas de forragem (13,9 e 31,2\%, respectivamente), o que permite maior seleção durante o pastejo e reflete no ganho médio diário (GMD), que foi de 93,6 e 92,0 g/animal/dia, respectivamente. O capim-andropogon apresentou apenas 4,4\% de lâmina foliar e promoveu GMD de 35,6 g/animal/dia $(\mathrm{P}<0,05)$. Dados estes obtidos por Menezes (2005), que se referem às avaliações das forragens e dos animais durante todo o período de engorda dos animais até o momento do seu abate, que contribuem para explicar os resultados de carcaça apresentados nesta pesquisa.

O peso ao abate pode interferir sobre o $\mathrm{PCQ}$, pois são altamente correlacionados $(r=0,94)$. Landim (2005) encontrou alta correlação $(r=0,99)$ entre essas caracterís- 
Tabela 2 - Peso vivo ao abate (PA), peso de carcaça quente (PCQ), rendimento de carcaça quente (RCQ), comprimento de carcaça (CC), escore de gordura de cobertura (EGC), peso da meia-carcaça quente (PMCQ) e dos cortes da meia-carcaça de ovinos terminados em pastejo nos capins adropogon, aruana ou tanzânia

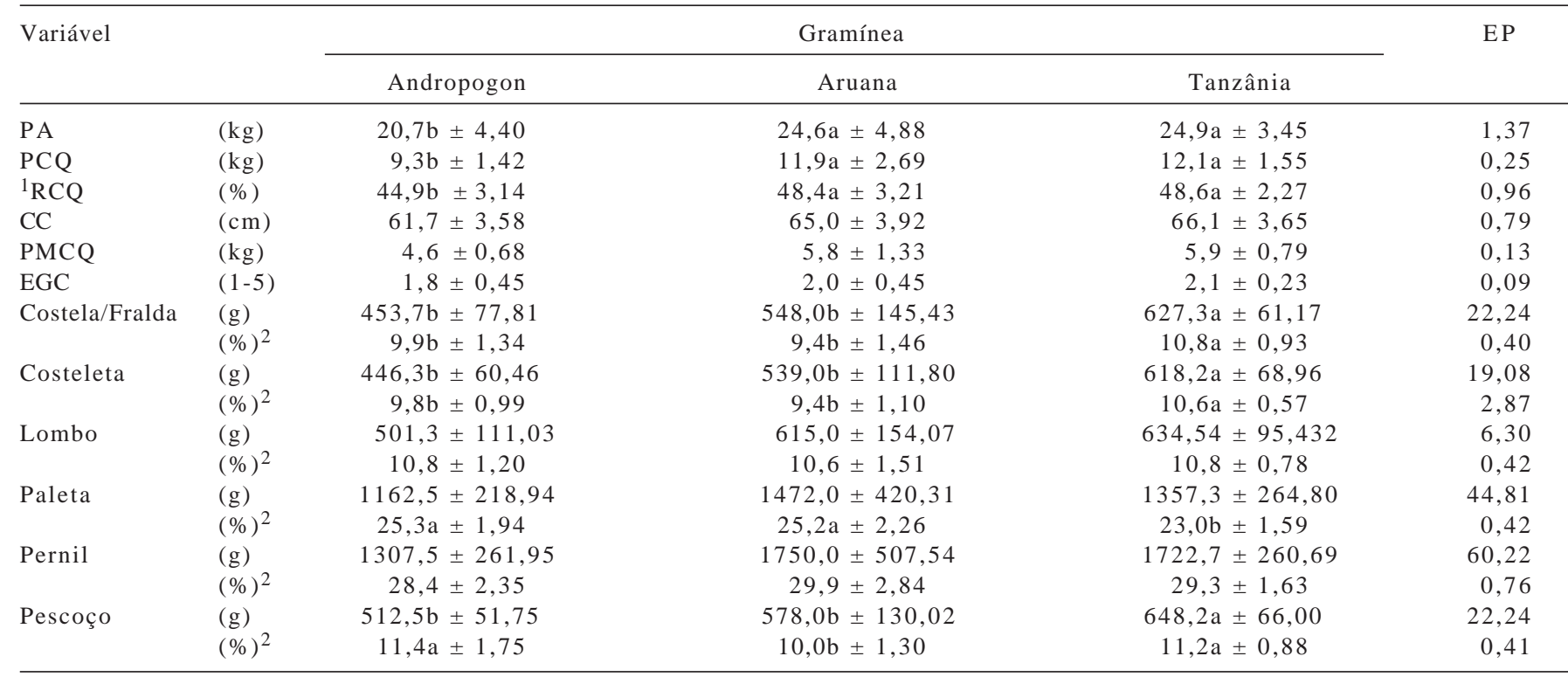

Médias seguidas de letras diferentes na mesma linha diferiram significativamente $(P<0,05)$; EP = erro-padrão.

1 Porcentagem relativa ao peso vivo ao abate (PA).

2 Porcentagens relativas ao peso da meia-carcaça quente (PMCQ).

ticas e demonstrou que o peso vivo, medida simples de ser realizada, é um bom indicador do rendimento de carcaça. O PCQ também apresentou correlação, porém baixa, com o $\operatorname{RCQ}(r=0,32)$ e esteve próximo ao resultado encontrado por Landim et al. (2005), de $r=0,24$, indicando que o quinto quarto pode interferir nesta correlação.

Em trabalho realizado por Díaz et al. (2002) com ovinos Talaverana em pastagem nativa, foram encontrados PCQ e RCQ de 12,0 kg e 48,0\%, respectivamente, portanto, a utilização de forrageiras tropicais associadas a suplementação com concentrado no período da seca possibilita a obtenção de resultados satisfatórios para produção de carcaças ovinas.

O desempenho dos ovinos criados em sistema de pastejo, PCQ (11,1 kg) e RCQ (47,3\%), foi próximo ao alcançado em outros trabalhos realizados com a raça Santa Inês, porém em confinamento: 12,2 kg e 46,6\% (Nunes et al., 2007); e 14,5 kg e 45,5\% (Alves et al., 2003).

A disponibilidade e qualidade da forragem são pontoschave no sistema a pasto e determinaram o menor desempenho para PA, PCQ e RCQ nos ovinos em pastagem de capimandropogon (Tabela 2), resultados semelhantes aos descritos por Moron-Fuenmayor \& Clavero (1999), de 23,1 kg, $10,0 \mathrm{~kg}$ e $43,7 \%$ em estudo com ovinos de raças africanas em pastagem de Cenchrus ciliaris; por Landim (2005), de $27,85 \mathrm{~kg}, 10,53 \mathrm{~kg}$ e $37,81 \%$; e por Louvandini et al. (2006), de 20,1 kg, 8,08 kg e 40,2\%, em pesquisa com ovinos Santa Inês em pastagem de capim-andropogon.
O abate do animal com maior peso poderia ser outra opção no manejo dos ovinos, mas, em experimento com a mesma raça em pastagem de andropogon com suplementação com concentrado, Veloso et al. (2004) abateram ovinos com 40,6 kg (PA) e obtiveram 18,8 kg de PCQ e 46,1\% de RCQ, comprovando que essa estratégia não representou grande vantagem em relação ao abate de animais mais leves. Ao contrário, essa escolha resulta em maior tempo de permanência dos cordeiros no sistema de pastejo, aumentando o ciclo de produção de carcaças e, conseqüentemente, a idade de abate dos animais, depreciando a qualidade de carcaça, uma vez que é privilegiada a deposição de gordura em detrimento à deposição de músculo e osso (Siqueira et al., 2001; Furusho-Garcia et al., 2003; Tonetto et al., 2004).

O peso ao abate e o PCQ apresentaram correlações positivas e elevadas com os pesos dos cortes de costela/ fralda, costeleta, lombo, paleta, pernil e pescoço; para o PA, as correlações foram 0,$69 ; 0,76 ; 0,82 ; 0,91 ; 0,90$ e 0,73 , respectivamente, e, para o PCQ, de 0,$82 ; 0,85 ; 0,87 ; 0,93$; 0,95 e 0,79 , respectivamente. As diferenças entre os tratamentos para os cortes da carcaça também podem ser explicadas pela diferença no PA e PCQ observada nos mesmos tratamentos. Além disso, o peso ao abate tem sido um bom parâmetro para avaliação de carcaça.

Apesar de o peso de paleta não ter diferido $(\mathrm{P}>0,05)$ entre os animais de todos os tratamentos, a porcentagem 
$(\mathrm{P}<0,05)$ deste corte na constituição da carcaça dos ovinos terminados em pasto de andropogon e aruana foi maior em comparação àqueles mantidos em capim-tanzânia. Este resultado pode ser explicado pelo desenvolvimento primário dos membros em relação ao flanco, confirmado pelas correlações negativas entre a porcentagens de paleta e pernil e as porcentagens de costela/fralda, costeleta e pescoço: $r=-0,72 ;-0,62$ e $-0,45$ er $=-0,45 ;-0,45$ e-0,68, respectivamente.

O desenvolvimento precoce dos membros (paleta e pernil) representa vantagem para abate de ovinos mais jovens, pois com o avançar da idade ocorre diminuição natural da participação destes cortes, mais nobres, na carcaça (Furusho-Garcia et al., 2004), o que também reflete nos pesos dos cortes costela/fralda, costeleta e pescoço (Tabela 2). Neste estudo, o capim-tanzânia proporcionou maiores médias $(\mathrm{P}<0,05)$, evidenciando que os animais mantidos em capim-tanzânia apresentaram desenvolvimento mais precoce e homogêneo dos cortes costilhares e de pescoço. Segundo Furusho-Garcia et al (2003), a característica racial dos ovinos Santa Inês, que apresentam pescoço mais longo, é uma desvantagem do ponto de vista comercial, pois este não é considerado corte nobre ou de primeira.

Segundo Díaz et al. (2002), os animais submetidos a sistema de pastejo possuem, proporcionalmente, maior participação dos cortes de dianteiro e costilhar em comparação a animais terminados em sistema de confinamento, que apresentam maior participação dos cortes de traseiro. Uma vez que todos os animais foram mantidos em sistema de pastejo, as diferenças entre os tratamentos está diretamente relacionada ao PA proporcionado pela forragem utilizada.

Apesar de não terem diferido na análise visual quanto à EGC (P>0,05), na análise da 12ª costela (Tabela 4), de maior precisão, a quantidade e proporção de gordura foram superiores nos ovinos mantidos nas pastagens dos capins aruana e tanzânzia em comparação àqueles terminados em capim-andropogon. O conhecimento das mudanças que alteram as proporções dos cortes comerciais, resultantes das mudanças metabólicas nas reservas energéticas para demanda do tecido muscular para o trabalho de locomoção durante o pastoreio, que afetam diretamente a cobertura da gordura da carcaça, principalmente na região dos cortes traseiros, é importante no sistema a pasto, pois o manejo desta deposição de tecidos é mais complicado na época da seca. Neste estudo, o EGC máximo alcançado foi de 2,1 para os animais mantidos em capim-tanzânia, valor considerado baixo em escala de até 5 .

Não houve diferenças $(\mathrm{P}>0,05)$ entre os pesos e as porcentagens de vísceras torácicas (VT), vísceras abdominais (VA) e testículos (TE) entre os animais (Tabela 3). Entretanto, os pesos desses componentes estiveram altamente correlacionados ao peso de abate $(r=0,79,0,75$ e 0,83 , respectivamente) e ao PCQ ( $\mathrm{r}=0,83,0,77$ e 0,79 , respectivamente). Os animais dos sistemas de terminação em capimaruana e capim-tanzânia não diferiram entre si $(\mathrm{P}>0,05)$ quanto ao peso de PELE, mas apresentaram as maiores médias $(\mathrm{P}<0,05)$, fato que pode estar relacionado aos menores valores de PA e PCQ dos ovinos terminados em pasto de capim-andropogon, uma vez que o peso de abate esteve altamente correlacionado ao peso de PELE $(r=0,78)$, enquanto o PCQ teve correlação moderada $(r=0,66)$, corroborando o resultado encontrado por Landim (2005). A interferência do quinto quarto justifica as diferenças entre o peso do animal e sua carcaça e, neste caso, utilizar o peso vivo do animal como único parâmetro de abate pode induzir erros.

Não houve diferenças entre os sistemas de terminação $(\mathrm{P}>0,05)$ quanto a AOLUS, PT, AOL, MUSC e para o peso de OSSO (Tabela 4). Observou-se alta correlação positiva entre a AOLUS e AOL $(r=0,73)$, corroborando os resultados descritos por McLaren et al. (1991), Hougthon \& Turlingthon

Tabela 3 - Pesos, em gramas, e porcentagens dos componentes não-carcaça em relação ao peso vivo do abate de ovinos terminados em pastos de capim-andropogon, capim-aruana ou capim-tanzânia

\begin{tabular}{|c|c|c|c|c|c|}
\hline \multirow[t]{2}{*}{ Variáve } & & \multicolumn{3}{|c|}{ Gramínea } & \multirow[t]{2}{*}{ EP } \\
\hline & & Andropogon & Aruana & Tanzânia & \\
\hline \multirow[t]{2}{*}{ Pele } & (g) & $1775,0 b \pm 631,89$ & $1930,0 \mathrm{a} \pm 757,26$ & $1804,5 a \pm 279,69$ & 108,71 \\
\hline & $(\%)$ & $8,5 \mathrm{a} \pm 1,72$ & $7,6 \mathrm{~b} \pm 1,67$ & $7,3 \mathrm{~b} \pm 0,87$ & 0,46 \\
\hline \multirow[t]{2}{*}{ VT } & (g) & $550,0 \pm 75,59$ & $650,00 \pm 176,38$ & $690,9 \pm 111,40$ & 29,78 \\
\hline & $(\%)$ & $2,7 \pm 0,37$ & $2,6 \pm 0,38$ & $2,8 \pm 0,38$ & 0,13 \\
\hline \multirow[t]{2}{*}{ VA } & (g) & $437,5 \pm 95,43$ & $510,0 \pm 227,06$ & $572,7 \pm 110,37$ & 37,27 \\
\hline & $(\%)$ & $2,1 \pm 0,38$ & $2,0 \pm 0,66$ & $2,3 \pm 0,33$ & 0,16 \\
\hline \multirow[t]{2}{*}{ TE } & (g) & $124,4 \pm 116,97$ & $204,5 \pm 112,46$ & $181,8 \pm 87,39$ & 20,17 \\
\hline & $(\%)$ & $0,5 \pm 0,35$ & $0,8 \pm 0,34$ & $0,7 \pm 0,26$ & 0,08 \\
\hline
\end{tabular}

Médias seguidas de letras diferentes na mesma linha diferiram significativamente $(P<0,05)$

$\mathrm{EP}$ = erro-padrão; VT = vísceras torácicas (coração + pulmão); VA = vísceras abdominais (fígado + rins); TE = testículos. 
Tabela 4 - Características da 12aㅡ costela de ovinos terminados em pastos de capim-andropogon, capim-aruana ou capim-tanzânia

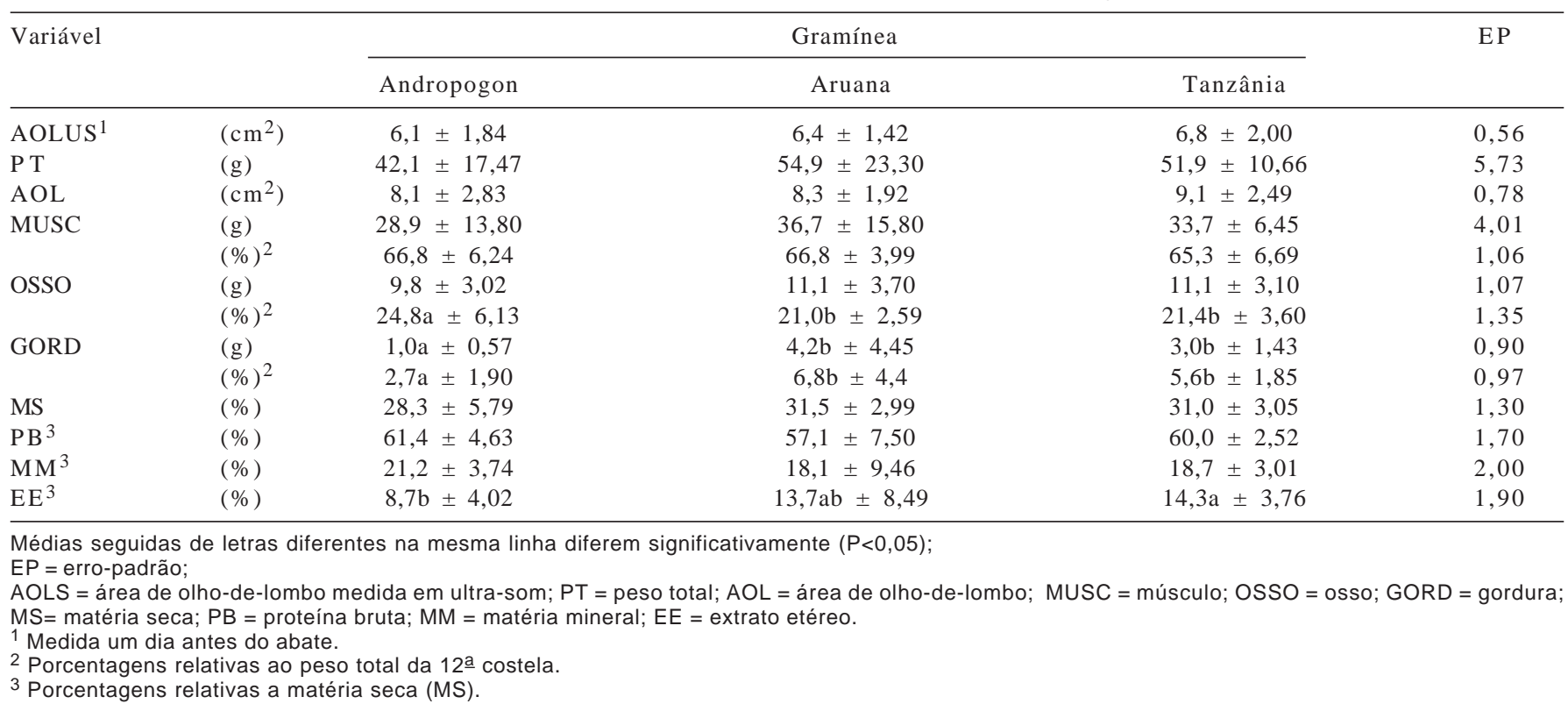

(1992) e Berg et al. (1997) e confirmando a importância da ultra-sonografia no acompanhamento da avaliação da massa muscular da carcaça. A avaliação por ultra-som apresentou subestimativa de aproximadamente $2 \mathrm{~cm}^{2}$.

Neste trabalho, o valor médio de AOL de todos os animais foi $8,5 \mathrm{~cm}^{2}$ e semelhante aos encontrados por Moron-Fuenmayor \& Clavero (1999), de 8,32 cm², em experimento com ovinos de raças africanas em pastagem de Cenchrus ciliaris; por Macedo et al. (2000), de 9,1 cm², com animais $1 \frac{1}{2}$ sangue Hampshire Down em pastagem de Cynodon dactylon; e por Louvandini et al. (2006), de $8,1 \mathrm{~cm}^{2}$, com ovinos Santa Inês em pastagem de capimandropogon. Assim, a quantidade de músculo da carcaça produzida, parte comercialmente mais valorizada, esteve dentro dos padrões dos ovinos.

O aspecto vantajoso da carcaça dos ovinos alimentados com os capins tanzânia e aruana, que não diferiram entre si, foi a menor proporção de osso da 12 a - costela em relação à carcaça dos animais terminados em capim-andropogon. Outro aspecto importante foi a maior participação de GORD na composição da costela dos animais terminados em pasto de capim-aruana e capim-tanzânia, que não diferiram entre si $(\mathrm{P}>0,05)$, em relação ao capim-andropogon $(\mathrm{P}<0,05)$. A gordura está diretamente relacionada à oferta energética da dieta e tem importante função na conformação, na proteção e nas características organolépticas da carcaça e de seus cortes (Poppi \& McLennan, 1995; Herselman et al., 1999). Assim, as variedades tanzânia e aruana utilizadas na alimentação dos ovinos foram determinantes do melhor acaba- mento de carcaça em detrimento àquelas obtidas com capim-andropogon, resultados confirmados também pela análise química da $12^{\mathrm{a}}$ costela.

Os resultados obtidos nas análises químicas da $12^{\underline{a}}$ costela estiveram dentro das variações encontradas por Landim (2005) e Louvandini et al. (2006). Embora os teores de EE e MM da 12 ${ }^{\text {a }}$ costela tenham acompanhado os resultados de gordura e osso, respectivamente, apenas o teor de EE foi maior nos animais terminados em pasto de capimtanzânia. Entre os animais terminados em capim-andropogon $(\mathrm{P}<0,05)$ e aqueles terminados em capim-aruana, houve tendência de diferença entre os sistemas de terminação $(\mathrm{P}=0,0859)$. Para os demais constituintes (MS e $\mathrm{PB})$, não houve diferenças significativas. A ingestão de quantidade excessiva de gordura de origem animal prejudica a saúde humana, fato que tem estimulado o consumidor à preferência por produtos menos gordurosos. Neste sentido, os ovinos terminados a pasto estariam mais próximos desta exigência de mercado.

\section{Conclusões}

Carcaças melhores são obtidas em ovinos alimentados com os capins aruana e tanzânia, em comparação ao capimandropogon, durante o período seco na região CentroOeste, com suplementação de concentrado. O gênero Panicum pode ser uma boa alternativa de substituição ao capim-andropogon, tradicionalmente utilizado na ovinocultura da Região Centro-oeste. 


\section{Agradecimento}

À Fazenda Nova Querência, em Luziânia (GO), pelos animais cedidos para a realização deste experimento; à Nutron e à Finatec, pelo apoio a esta pesquisa.

\section{Literatura Citada}

AGRICULTURAL AND FOOD RESEARCH COUNCIL - AFRC. Energy and Protein requirement of ruminants. Advisory manual prepared by AFRC technical Committiee on Responses to nutrients. Wallingford: CAB International, 1993. p.159.

ALVES, K.S.; CARVALHO, F.F.R.; FERREIRA, M.A. et al. Níveis de energia em dietas para ovinos Santa Inês: características de carcaça e constituintes corporais. Revista Brasileira de Zootecnia, v.32, n.6, p.1927-1936, 2003.

ASSOCIATION OF OFICIAL AGRICULTURAL CHEMISTS AOAC. Official methods of analysis of AOAC. 16.ed. Arligton: AOAC International, 1955, v.1, p.4-30.

AZEREDO, D.M.; OSÓRIO, M.T.M.; OSÓRIO, J.C.S. et al. Morfologia in vivo e da carcaça e características produtivas e comerciais em ovinos Corriedale não castrados, castrados e criptorquidas abatidos em diferentes idades. Revista Brasileira de Agrociências, v.12, n.2, p.199-204, 2006.

BERG, E.P.; NEARY, M.K.; FORREST, J.C. et al. Evaluation of eletronic technology to assess lambs carcass composition. Journal of Animal Science, v.75, n.9, p.2433-2444, 1997.

DÍAZ, M.T.; VELASCO, S.; CAÑEQUE, V. et al. Use of concentrate or pasture for fattening lambs and its effect on carcass and meat quality. Small Ruminant Research, v.43, n.3, p.257268, 2002.

FRESCURA, R.B.M.; PIRES, C.C.; SILVA, J.H.S. et al. Avaliação das proporções dos cortes da carcaça, características da carne e avaliação dos componentes do peso vivo de cordeiros. Revista Brasileira de Zootecnia, v.34, n.1, p.167-174, 2005.

FURUSHO-GARCIA, I.F.; PEREZ, J.R.O.; TEXEIRA, J.C. Componentes de carcaça e composição de alguns cortes de cordeiros Texel $\times$ Bergamácia, Textel $\times$ Santa Inês e Santa Inês puros, terminados em confinamento, com casca de café como parte da dieta. Revista Brasileira de Zootecnia, v.32, n.6, p.1999-2006, 2003.

FURUSHO-GARCIA, I.F.; PEREZ, J.R.; BONAGURIO, S. et al. Estudos dos cortes de cordeiros santa inês puros e cruzas Santa Inês com Textel, Ile de France e Bergamácia. Revista Brasileira de Zootecnia, v.33, p.453-462, 2004;

HANKINS, O.G.; HOWE, P.E. Estimation of composition of beef carcasses and cuts. Washingthon, D.C.: 1946. 20p. (Techinical Bulletin, 926).

HERSELMAN, M.J.; HART, S.P.; SAHLU, T. et al. Heat energy for growing goats and sheep grazing different pastures in the Summer. Journal of Animal Science, v.77, n.5, p.1258-1265, 1999.

HOUGTHON, P.L.; TURLINGTON, L.M. Aplication of ultrasound for feeding and finishing animals: a review. Journal of Animal Science, v.70, n.3, p.930-941, 1992.

JARDIM, R.D.; OSÓRIO, J.C.S.; OSÓRIO, M.T.M. et al. Efeito do sistema de criação sobre os componentes corporais em cordeiros da raça Corriedale. Revista Brasileira de Agrociência, v.8, n.3, p.237-240, 2002
LANDIM, A.V. Desempenho e qualidade de carcaça em ovinos cruzados no Distrito Federal. Brasília: Faculdade de Agronomia e Medicina Veterinária, 2005. 81p. Dissertação (Mestrado em Ciências Agrárias) - Universidade de Brasília, 2005.

LOUVANDINI, H.; McMANUS, C.M.; DALLAGO, B.S. et al. Evaluations of carcass traits, non-carcass components and $12^{\text {th }}$ rib analysis of hair sheep supplemented with phosphorus. Revista Brasileira de Zootecnia, v.35, n.2, p.550-554, 2006.

MACEDO, F.A.F.; SIQUEIRA, E.R.; MARTINS, E.N. et al. Qualidade de carcaça de cordeiros Corriedale, Bergamácia $\times$ Corriedale e Hampshire Down $\times$ Corriedale, terminados em pastagem e confinamento. Revista Brasileira de Zootecnia, v.29, n.5, p.1520-1527, 2000.

McLAREN, D.G.; NOVAKOFSKI, J.; PARRETT, D.F. et al. A Study of effects on ultrasonic measures of fat depth and Longissimus muscle area in cattle, sheep and pigs. Journal of Animal Science, v.69, n.1, p.54-66, 1991.

MENDONÇA, G.; OSÓRIO, J.C.; OLIVEIRA, N.M. et al. Morfologia, características de carcaça e componentes do peso vivo em borregos Corriedale e Ideal. Ciência Rural, v.33, n.2, p.351-355, 2003.

MORON-FUENMAYOR, O.E.; CLAVERO, T. The effect of feeding system on carcass characteristics, non-carcass components ans retail cut percentages of lambs. Small Ruminant Reserch, v.34, n.1, p.57-64, 1999.

NUNES, G.A.; LOUVANDINI H.; ARAÚJO S.C. et al. Desempenho, características de carcaça e constituintes corporais de ovinos Santa Inês alimentados com farelo de girassol em substituição ao farelo de soja na dieta. Revista Brasileira de Zootecnia, v.36, n.3, p.603-609, 2007.

OSÓRIO, J.C.S.; OSÓRIO, M.T.; JARDIM, P.O. et al. Métodos para avaliação da produção da carne ovina: in vivo na carcaça e na carne. Pelotas: Universidade Federal de Pelotas, 107p. 1998.

POPPI, D.P; McLENNAN, S.R. Protein and energy utilization by ruminants at pasture. Journal of Animal Science, v.73, n.1, p.278-290, 1995.

STATISTICAL ANALYSIS SYSTEM - SAS. SAS System for Windows: version 8.0. Cary: SAS Institute, 1999. (CD-ROM).

SERVIÇO BRASILEIRO DE APOIO ÀS MICRO E PEQUENAS EMPRESAS - SEBRAE. Informações de mercado sobre caprinos e ovinos: relatório completo. Brasília: SEBRAE, 2005. 73p.

SILVA, D.J.; QUEIROZ, A.C. Análise de alimentos: métodos químicos e biológicos. 3.ed. Viçosa, MG: Editora UFV, 2002. 235p.

SIQUEIRA, E.R.; SIMÕES, C.D.; FERNANDES, S. Efeito do sexo e do peso ao abate sobre a produção de carne de cordeiro. I. Velocidade de crescimento, caracteres quantitativos da carcaça, $\mathrm{pH}$ da carne e resultado econômico. Revista Brasileira de Zootecnia, v.30, n.3, p.844-848, 2001.

TONETTO, C.J.; PIRES, C.C.; MÜLLER, L. et al. Ganho de peso e características da carcaça de cordeiros terminados em pastagem natural suplementada, pastagem cultivada de azevém (Lolium multiflorum Lam.) e confinamento. Revista Brasileira de Zootecnia, v.33, n.1, p.225-233, 2004.

VELOSO, C.F.M.; LOUVANDINI, H.; KIMURA, E.A. et al. Efeito da suplementação protéica na verminose e nas características de carcaças de ovinos da raça Santa Inês mantidos a pasto. Ciência Animal Brasileira, v.5, n.3, p.131-139, 2004. 